\title{
Laparoscopic RFA with splenectomy for hepatocellular carcinoma
}

\author{
Kunpeng $\mathrm{Hu}^{1 \dagger}$, Purun Lei ${ }^{2 \dagger}$, Zhicheng Yao ${ }^{1 \dagger}$, Chenhu Wang ${ }^{3}$, Qingliang Wang ${ }^{1}$, Shilei Xu', Zhiyong Xiong ${ }^{4}$, \\ He Huang ${ }^{1}$, Ruiyun $\mathrm{Xu}^{4}$, Meihai Deng ${ }^{4}$ and Bo Liu ${ }^{1^{*}}$
}

\begin{abstract}
Background: The treatment of hepatocellular carcinoma (HCC) is complicated and challenging because of the frequent presence of cirrhosis. Therefore, we propose a novel surgical approach to minimize the invasiveness and risk in patients with HCC, hypersplenism, and esophagogastric varices.

Methods: This was a retrospective study carried out in 25 patients with HCC and hypersplenism and who underwent simultaneous laparoscopic-guided radio-frequency ablation and laparoscopic splenectomy with endoscopic variceal ligation. Tumor size was restricted to a single nodule of $<3 \mathrm{~cm}$. Characteristics of the patients (cirrhosis etiology, liver function, tumor size, spleen size), surgery (complications, blood loss, time of stay), and follow-up (recurrence and survival) were examined.

Results: Mean operative time was $128 \pm 18 \mathrm{~min}$. Mean blood loss was $206 \pm 57 \mathrm{~mL}$. Length of stay was $7.0 \pm 1$. 5 days. Mean total costs were 8064 USD. Cytopenia and thrombocytopenia recovered quickly after surgery. No procedure was converted to open surgery. Two patients showed worsening liver function after surgery, three patients showed worsening of ascites, and five patients suffered from portal vein thrombosis. The 1-year tumor-free survival was $78.8 \%$, and the 21 -month tumor-free survival was $61.4 \%$. According to a literature review, these outcomes were comparable to those of simultaneous open hepatic resection and splenectomy.

Conclusions: Laparoscopic-guided radio-frequency ablation with laparoscopic splenectomy and endoscopic variceal ligation could be an available technique for patients with $\mathrm{HCC}<3 \mathrm{~cm}$, hypersplenism, and esophagogastric varices. This approach may help to minimize the surgical risks and results in a fast increase in platelet counts with an acceptable rate of complications.
\end{abstract}

Keywords: Hepatocellular carcinoma, Hypersplenism, Laparoscopy, Ablation, Splenectomy, Endoscopic variceal ligation

\section{Background}

Hepatocellular carcinoma (HCC) is one of most common cancers in China [1]. The treatment of HCC is complicated and challenging due to the frequent presence of hepatic cirrhosis and portal hypertension, which may result in coagulation dysfunction, esophagogastric varices, anemia, abdominal collaterals, and peripheral cytopenia, particularly thrombocytopenia [2-5].

Therefore, treatment for HCC should remove the tumor with minimal invasiveness. Cirrhotic hypersplenism can result in peripheral cytopenia. Because cytopenia is

\footnotetext{
* Correspondence: liubojake@126.com

${ }^{\dagger}$ Equal contributors

'Department of General Surgery, The Third Affiliated Hospital, Sun Yat-sen

University, Guangzhou 510000, China

Full list of author information is available at the end of the article
}

reversible after splenectomy, splenic embolism or resection seems to be an appropriate choice. Simultaneous hepatectomy and splenectomy are associated with improved 5-year tumor-free survival in patients with HCC and hypersplenism [6], and laparoscopic splenectomy (Lap-sp) has recently become a potential choice [7]. Moreover, radio-frequency ablation (RFA) has been reported to have the same outcomes as liver resection for patients with tumors $<3 \mathrm{~cm}[8-10]$.

In an animal model, splenectomy improved the status of hepatic cirrhosis [11] and helped hepatic recovery, promoting liver regeneration after massive liver resection [12]. Recently, some studies reported that liver function was improved after splenectomy in patients with portal hypertension and hypersplenism. 
Therefore, the objective of this study was to investigate the effects of laparoscopic-guided RFA with Lap-sp and endoscopic variceal ligation in patients with $\mathrm{HCC}<3 \mathrm{~cm}$, cirrhosis, and esophagogastric varices.

\section{Methods}

\section{Patients}

This was a retrospective study carried out in 25 patients with $\mathrm{HCC}$, hypersplenism, and esophagogastric varices and who underwent simultaneous laparoscopic-guided ablation and Lap-sp with endoscopic variceal ligation between January 2012 and October 2014 at the Department of General Surgery at the Third Affiliated Hospital of Sun Yat-sen University (Guangzhou, China). Informed contents were accepted and signed off by all patients and their family members before surgery. The study was approved by the Committee of Ethics of the Third Affiliated Hospital of Sun Yat-sen University. Written informed consent was obtained from the patient for the publication of this report and any accompanying images.

At our center, selection criteria for this surgical approach were (1) 18-70 years old; (2) diagnosis of HBVor HCV-related liver cirrhosis with portal hypertension; (3) spleen thickness $>4.1 \mathrm{~cm}$; (4) $\mathrm{HCC} \leq 3 \mathrm{~cm}$; (5) first surgical attempt; (6) severe esophagogastric varicosity confirmed by gastroscopy; (7) Child-Pugh class A or B, score $\leq 9$; and (8) platelets $\leq 50 \times 10^{9} / \mathrm{L}$ and leukocytes $\leq 3.5 \times 10^{9} / \mathrm{L}$. This approach was not proposed to patients in case of (1) other tumors; (2) HIV-positive test; (3) any immunodeficiency or autoimmune disease (e.g., rheumatic arthritis, Buerger's disease, multiple sclerosis, type 1 diabetes); (4) any organ failure; or (5) mental illness.

\section{Surgical procedure}

Surgery was performed under general anesthesia with the patient in the right semi-decubitus position. Five trocars with a diameter of $5 \mathrm{~mm} / 12 \mathrm{~mm}$ were introduced into the abdominal cavity through the left upper quadrant of the abdomen. The abdominal cavity was insufflated with 13-15 $\mathrm{mmHg}$ of $\mathrm{CO}_{2}$, and a $30^{\circ}$ laparoscope was inserted. Mobilization of the spleen was performed using the Ligasure vessel sealing system and an ultrasonic scalpel. The tissues around the splenic hilum including the splenic arteries and veins were cut using an autosuture device, and the spleen was freed. The spleen was packed in a plastic sac and cut into pieces using scissors through one of the trocar ports. The fragmented spleen was then removed with the sac from the abdomen without extending the wound. Next, the RFA needle was inserted into the center of the target $\mathrm{HCC}$ nodule by the radiologist. RFA was applied continuously for 8-12 min. The endpoint of RFA was determined mainly according to ultrasonography of an index tumor that was fully covered by the hyperechoic ablated zone. Finally, endoscopic ligation was performed as classically described [13]. All patients were treated by the same surgical team. An empirical course of antibiotics was started 30 min before surgery and was later adjusted based on the results of bacterial cultures. The duration was $48 \mathrm{~h}$ on cases of negative results.

\section{Follow-up}

Blood routine examination, liver function, and color Doppler ultrasound were performed on days 3, 7, 14, and 30, months 2 and 3, and then every 3 months. Virology, CT, and gastroscopy were performed every 3 months after surgery. Follow-up was censored in October 2014 or at the time of death.

\section{Statistical analysis}

Statistical analysis was performed with SPSS 20.0 (IBM, Armonk, NY, USA). Continuous variables are presented as mean \pm standard deviation. Categorical variables are presented as frequencies. The Kaplan-Meier method was used to present overall survival (OS) and disease-free survival (DFS). DFS was defined as the time from initial treatment to the first evidence of recurrence. Survival was censored at the last follow-up. Two-tailed $P$ values $<0.05$ were considered significant.

\section{Results}

\section{Characteristics of the patients}

This study included 24 men and 1 woman (mean age $51.5 \pm 15.0$ years). All patients had symptoms of hepatic cirrhosis and portal hypertension, and HBV infection $(21 / 25)$ was the main cause, followed by HCV (3/25) and co-infection (1/25). Alcohol abuse history was present in ten patients. Mean tumor size was $20.0 \pm$ $4.6 \mathrm{~mm}$ (range 13-28 $\mathrm{mm}$ ) and spleen thickness was $>4.1 \mathrm{~cm}$ and length was $18.4 \pm 2.5 \mathrm{~cm}$ (range 14-22 cm (Table 1).

\section{Perioperative characteristics}

No cases had to be converted to an open procedure. All patients tolerated the operations well without major intraoperative complications (Table 2).

\section{Postoperative outcomes}

No patient had a positive bacterial culture test or became febrile. Portal vein thrombosis occurred in five patients. Three patients had worsening ascites after surgery, two of whom showed increases in bilirubin levels, manifesting the deterioration in liver function. The mean length of stay was $7.0 \pm 1.5$ days (range $5-15$ days). The mean costs of hospitalization were 8064 USD. 
Table 1 Baseline characteristics of the patients

\begin{tabular}{|c|c|}
\hline Characteristics & Values $(n=25)$ \\
\hline Age $($ mean $\pm S D)$ & $51.52 \pm 15.03$ \\
\hline Gender (male/female) & $24 / 1$ \\
\hline Portal hypertension & 25 \\
\hline \multicolumn{2}{|l|}{ Etiology of cirrhosis } \\
\hline HBV & 21 \\
\hline $\mathrm{HCV}$ & 3 \\
\hline $\mathrm{HBV}+\mathrm{HCV}$ & 1 \\
\hline Alcoholic & 10 \\
\hline \multirow[t]{2}{*}{ Child-Pugh classification } & A $20(80 \%)$ \\
\hline & B 5 (20\%) \\
\hline \multicolumn{2}{|l|}{ Serum AFP $(\mu \mathrm{g} / \mathrm{L})$} \\
\hline$\leq 20$ & $12(48 \%)$ \\
\hline $20-400$ & $7(28 \%)$ \\
\hline$>400$ & $6(24 \%)$ \\
\hline Tumor number & $1(n=25)$ \\
\hline Tumor size (mm) & $20 \pm 4.56$ \\
\hline$\leq 20$ & $17(68 \%)$ \\
\hline $20-30$ & $8(32 \%)$ \\
\hline Mean HBV DNA load (log10 IU/mL) & $3.10 \pm 1.59$ \\
\hline Platelet count $\left(\times 10^{9} / \mathrm{L}\right)($ mean \pm SD) & $31.16 \pm 6.92$ \\
\hline White blood cell count $\left(\times 10^{9} / \mathrm{L}\right)($ mean $\pm \mathrm{SD})$ & $3.81 \pm 0.62$ \\
\hline $\mathrm{ALT}(\mathrm{IU} / \mathrm{L})($ mean $\pm \mathrm{SD})$ & $41.36 \pm 33.76$ \\
\hline $\mathrm{AST}(\mathrm{IU} / \mathrm{L})($ mean $\pm \mathrm{SD})$ & $39.80 \pm 24.91$ \\
\hline Albumin $(\mathrm{g} / \mathrm{L})($ mean $\pm \mathrm{SD})$ & $41.17 \pm 3.68$ \\
\hline Bilirubin $(\mu \mathrm{mol} / \mathrm{L})($ mean $\pm S D)$ & $15.36 \pm 4.99$ \\
\hline Length of spleen $(\mathrm{cm})$ & $18.36 \pm 2.46$ \\
\hline
\end{tabular}

AFP a-fetoprotein, $H B V$ hepatitis B virus, $H C V$ hepatitis $C$ virus, $A L T$ alanineaminotransferase, $A S T$ aspartate aminotransferase, $S D$ standard deviation

\section{Changes in blood cell counts}

The average platelet counts were 31.16, 101.02, 334.52, 378.34 , and $349.78 \times 10^{9} / \mathrm{L}$ before surgery and on days 3 , 7 , 14 , and 30 , respectively $(P<0.05)$. White blood cell counts also showed the same trend $(3.81,9.56,7.23,6.68$,

Table 2 Intraoperative and postoperative complications

\begin{tabular}{lll}
\hline Complications & Number & Percent \\
\hline Converted to open surgery & 0 & 0 \\
Hemorrhage & 0 & 0 \\
Bile leakage & 0 & 0 \\
Infection of port(s) & 0 & 0 \\
Hepatic encephalopathy & 0 & 0 \\
Hepatorenal syndrome & 0 & 0 \\
Postoperative deterioration in liver function tests & 2 & 8 \\
Postoperative worsening of ascites & 3 & 12 \\
Portal vein thrombosis & 5 & 20 \\
\hline
\end{tabular}

and $6.15 \times 10^{9} / \mathrm{L}$, respectively). In addition, the mean total bilirubin levels were 15.36, 28.92, 25.42, 21.03, and 16.44 $\mu \mathrm{mol} / \mathrm{L}$, respectively. These parameters changed during the first month and then remained stable (Fig. 1).

\section{Follow-up}

All patients were followed up (1-21 months). Six patients had HCC recurrence (11-17 months), and one patient died of HCC 14 months after surgery. DFS at 21 months was $61.4 \%$ in all patients (Table 3 and Fig. 2).

\section{Discussion}

Recently, some studies reported that liver function was improved after splenectomy in patients with portal hypertension and hypersplenism. A study by Shimada et al. [14] suggested improvements in Child-Pugh scores after splenectomy, while Imura et al. [15] demonstrated an additional improvement in nutritional metabolism after splenectomy.

Because the residual splenic tissue remaining after partial embolism may regenerate [16], spleen embolism has not been demonstrated to decrease the total bilirubin levels and may not relieve hypersplenism sufficiently to improve liver function $[17,18]$. In addition, the timing of splenectomy is controversial. Hanazaki et al. [19] and Shimada et al. [14] suggested that splenectomy should be performed first, followed by hepatectomy, because portal vein thrombosis occurs frequently after synchronous splenectomy and increases the morbidity of the procedure. Meanwhile, Sugawara et al. [17] suggested that when HCC is located at the left lobe and superficial region of the liver, synchronous splenectomy and liver resection are beneficial because the left lobe is located near the spleen, making the hepatectomy procedure much easier. For tumors located at the right lobe of the liver, they suggested staged splenectomy first and hepatectomy 30 to 58 days later [17].

Previous studies showed the feasibility of synchronous splenectomy and liver resection without compromising perioperative safety $[17,18,20-22]$. Chen et al. [6] reported that synchronous open hepatectomy and splenectomy were associated with an improved 5-year DFS.

Synchronous laparoscopic-guided RFA with Lap-sp and endoscopic variceal ligation is safe and feasible, not only minimizing invasiveness but also avoiding spleen regeneration. In this series, no hemorrhage or conversion occurred during the perioperative period. In the previous studies, the mean operative time and blood loss were 103-305 $\mathrm{min}$ and 380-1300 $\mathrm{mL}$, respectively $[6,17,18,20-22]$. In the current study, they were $128 \pm$ $18 \mathrm{~min}$ and $206 \pm 57 \mathrm{~mL}$, respectively, suggesting that this approach could significantly reduce both parameters. Patients also had a shorter length of stay without compromising safety (7 vs. 13.2 days) [18]. 

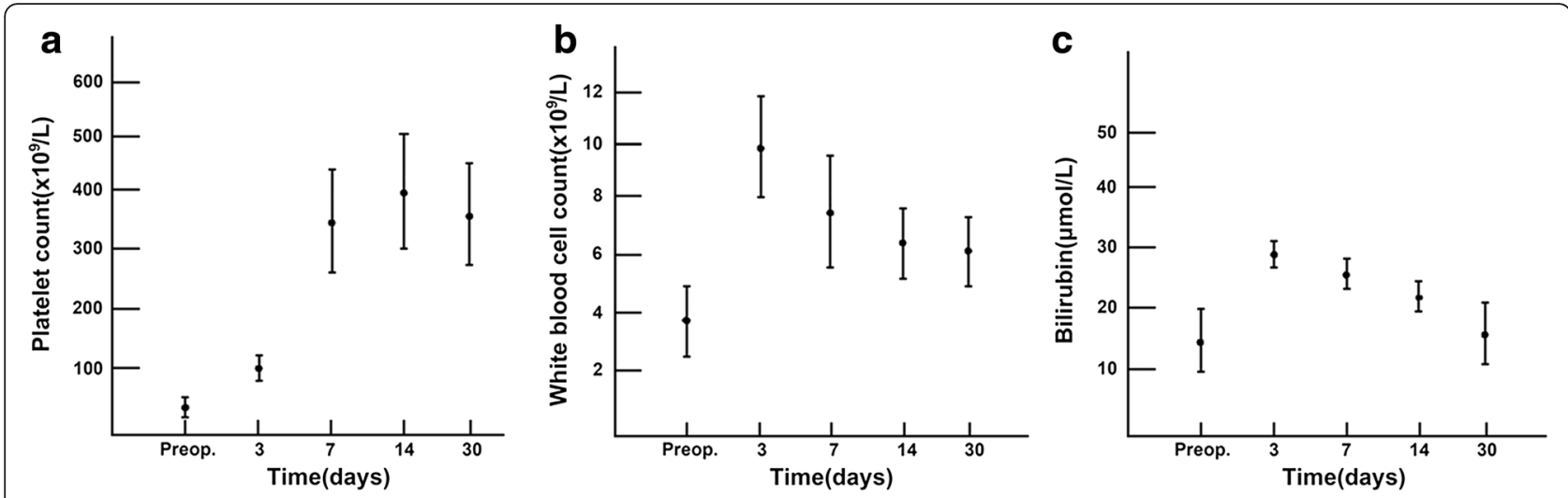

Fig. 1 Preoperative and postoperative platelet counts (a), white blood cell counts (b), and total bilirubin levels (c)

The frequency of portal vein thrombosis after splenectomy has been reported to range from 2 to $48 \%$ in patients with cirrhosis or portal hypertension [23], and $50 \%$ in non-cirrhotic patients [24]. The prevalence of operative mortality from portal vein thrombosis after splenectomy ranged from 0 to $18 \%[17,19]$, compared to $20 \%$ in this present study. The diameter of the splenic vein, low white blood cell counts, and spleen weight were reported as being independent risk factors for portal vein thrombosis [25]. Regarding portal vein thrombosis, the risk factors should be more strictly evaluated, managed, and treated in a future study.

High bilirubin levels secondary to hypersplenism is caused by an increase in bilirubin production, which overloads the capacity of the liver to metabolize bilirubin [26]. Splenectomy might contribute to the decrease of total bilirubin levels, but it is difficult to demonstrate any direct contribution, and postoperative care to protect liver function could also have some influence. Splenectomy has been suggested for the treatment of secondary hypersplenism and thrombocytopenia [27]. Some investigators have carried out splenectomy for patients who had undergone liver transplantation complicated by persistent thrombocytopenia [28]. Takayama et al. [26] and Sugawara et al. [17] used this procedure to extend the patient selection criteria for HCC resection in cirrhotic patients.

Table 3 Recurrence, overall survival, and disease-free survival

\begin{tabular}{ll}
\hline Patients $(n=25)$ & Percent \\
\hline Recurrence & 24 \\
Overall survival & \\
1 year & 100 \\
21 months & 96 \\
Disease-free survival & \\
1 year & 78.8 \\
21 months & 61.4 \\
\hline
\end{tabular}

Previous studies showed that the 1-year survival of patients who underwent simultaneous liver resection and splenectomy is $82-90 \%[6,17,18,20-22]$ and that the 1 -year DFS is $80 \%[6,22]$, which are similar to this present series. However, in the study by Chen et al. [6], the 5-year DFS was significantly higher. Future studies may help to clarify these issues.

This study was a retrospective and uncontrolled pilot study comparing using previously reported results as comparator. Prospective studies of Lap-sp and splenectomy for HCC patients are necessary.

\section{Conclusions}

In conclusion, laparoscopic-guided ablation with Lap-sp and endoscopic variceal ligation could be an elective technique for patients with $\mathrm{HCC}<3 \mathrm{~cm}$, hypersplenism, and esophagogastric varices. The approach seems to

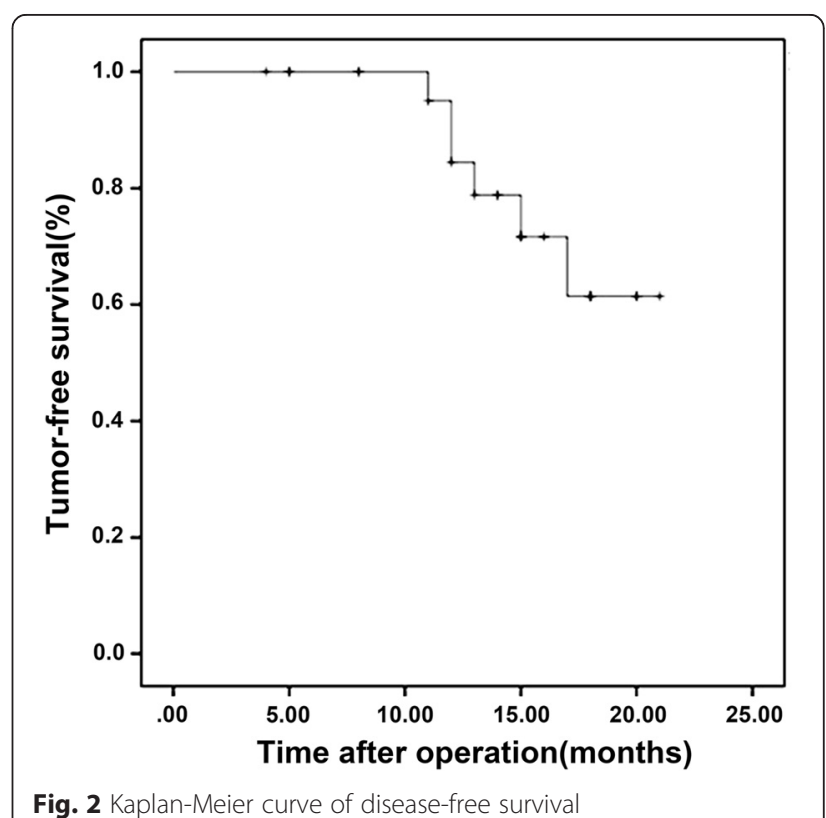


minimize the risks and to result in a fast recovery of the platelet count with an acceptable rate of complications. Although the long-term outcomes after this procedure remain to be determined, future randomized controlled prospective studies are needed to confirm these findings.

\section{Abbreviations}

DFS, disease-free survival; HCC, hepatocellular carcinoma; Lap-sp, laparoscopic splenectomy; OS, overall survival; RFA, radio-frequency ablation

\section{Acknowledgements}

None.

\section{Funding}

This work was supported by Science and Technology Planning Project of Guangdong Province, China, 2014A020212715.

\section{Availability of data and materials}

Our data will not be shared temporarily because the data will be used in another study of our series research about laparoscopic splenectomy.

\section{Authors' contributions}

$\mathrm{KH}, \mathrm{QW}, \mathrm{SX}, \mathrm{ZX}, \mathrm{HH}, \mathrm{RX}$, and MD carried out the study and drafted the manuscript. $\mathrm{KH}, \mathrm{PL}$, and $\mathrm{ZY}$ carried out the data collection. $\mathrm{KH}$ and $\mathrm{CW}$ participated in the design of the study and performed the statistical analysis. $\mathrm{BL}$ conceived of the study, participated in its design and coordination, and helped to draft the manuscript. All authors read and approved the final manuscript.

\section{Competing interests}

The authors declare that they have no competing interests.

\section{Consent for publication}

Written informed consent was obtained from the patient for the publication of this report and any accompanying images.

\section{Ethics approval and consent to participate}

1. Informed contents were accepted and signed off by all patients and their family members before surgery.

2. The study was approved by the Committee of Ethics of the Third Affiliated Hospital of Sun Yat-sen University.

\section{Author details}

'Department of General Surgery, The Third Affiliated Hospital, Sun Yat-sen University, Guangzhou 510000, China. ${ }^{2}$ Department of Gastrointestinal Surgery, The Third Affiliated Hospital, Sun Yat-sen University, Guangzhou 510000, China. ${ }^{3}$ Department of General Surgery, Affiliated Hospital of Jiangnan University, Wuxi 214000, China. ${ }^{4}$ Department of Hepatobiliary Surgery, The Third Affiliated Hospital, Sun Yat-sen University, Guangzhou 510000, China.

Received: 14 January 2016 Accepted: 20 July 2016

Published online: 27 July 2016

\section{References}

1. Li C, Zhao H, Zhao J, Li Z, Huang Z, Zhang Y, et al. Prognosis of patients with hepatocellular carcinoma and hypersplenism after surgery: a singlecenter experience from the People's Republic of China. Onco Targets Ther. 2014;7:957-64.

2. Yao Z, Hu K, Huang P, Huang H, Chen X, Yang P, et al. Delayed laparoscopic cholecystectomy is safe and effective for acute severe calculous cholecystitis in patients with advanced cirrhosis: a single center experience. Gastroenterol Res Pract. 2014;2014:178908.

3. Morise Z, Kawabe N, Tomishige H, Nagata H, Kawase J, Arakawa S, et al. Recent advances in the surgical treatment of hepatocellular carcinoma. World J Gastroenterol. 2014;20(39):14381-92.

4. Han DH, Choi GH, Park JY, Ahn SH, Kim KS, Choi JS, et al. Lesson from 610 liver resections of hepatocellular carcinoma in a single center over 10 years. World J Surg Oncol. 2014;12:192.
5. Clinical Practice Guidelines in Oncology (NCCN Guidelines). Hepatobiliary cancers. Version 2.2015. Fort Washington: National Comprehensive Cancer Network; 2015.

6. Chen XP, Wu ZD, Huang ZY, Qiu FZ. Use of hepatectomy and splenectomy to treat hepatocellular carcinoma with cirrhotic hypersplenism. Br J Surg. 2005:92(3):334-9.

7. Tomikawa M, Akahoshi T, Sugimachi K, Ikeda Y, Yoshida K, Tanabe Y, et al. Laparoscopic splenectomy may be a superior supportive intervention for cirrhotic patients with hypersplenism. J Gastroenterol Hepatol. 2010;25(2):397-402.

8. Fang Y, Chen W, Liang X, Li D, Lou H, Chen R, et al. Comparison of long-term effectiveness and complications of radiofrequency ablation with hepatectomy for small hepatocellular carcinoma. J Gastroenterol Hepatol. 2014;29(1):193-200.

9. Hasegawa K, Kokudo N, Makuuchi M, Izumi N, Ichida T, Kudo M, et al. Comparison of resection and ablation for hepatocellular carcinoma: a cohort study based on a Japanese nationwide survey. J Hepatol. 2013;58(4):724-9.

10. Shi J, Sun Q, Wang Y, Jing X, Ding J, Yuan Q, et al. Comparison of microwave ablation and surgical resection for treatment of hepatocellular carcinomas conforming to Milan criteria. J Gastroenterol Hepatol. 2014;29(7):1500-7.

11. Akahoshi T, Hashizume M, Tanoue K, Shimabukuro R, Gotoh N, Tomikawa M, et al. Role of the spleen in liver fibrosis in rats may be mediated by transforming growth factor beta-1. J Gastroenterol Hepatol. 2002;17(1):59-65.

12. Arakawa Y, Shimada M, Uchiyama H, Ikegami T, Yoshizumi T, Imura S, et al. Beneficial effects of splenectomy on massive hepatectomy model in rats. Hepatol Res. 2009;39(4):391-7.

13. Lin N, Liu B, Xu RY, Fang HP, Deng MH. Splenectomy with endoscopic variceal ligation is superior to splenectomy with pericardial devascularization in treatment of portal hypertension. World J Gastroenterol. 2006;12(45):7375-9.

14. Shimada M, Hashizume M, Shirabe K, Takenaka K, Sugimachi K. A new surgical strategy for cirrhotic patients with hepatocellular carcinoma and hypersplenism. Performing a hepatectomy after a laparoscopic splenectomy. Surg Endosc. 2000;14(2):127-30.

15. Imura $\mathrm{S}$, Shimada M, Utsunomiya $\mathrm{T}$, Morine $\mathrm{Y}$, Ikemoto $\mathrm{T}$, Mori $\mathrm{H}$, et al. Impact of splenectomy in patients with liver cirrhosis: results from 18 patients in a single center experience. Hepatol Res. 2010;40(9):894-900.

16. Lee CM, Leung TK, Wang HJ, Lee WH, Shen LK, Liu JD, et al. Evaluation of the effect of partial splenic embolization on platelet values for liver cirrhosis patients with thrombocytopenia. World J Gastroenterol. 2007;13(4):619-22.

17. Sugawara Y, Yamamoto J, Shimada K, Yamasaki S, Kosuge T, Takayama T, et al. Splenectomy in patients with hepatocellular carcinoma and hypersplenism. J Am Coll Surg. 2000;190(4):446-50.

18. Wu CC, Cheng SB, Ho WM, Chen JT, Yeh DC, Liu TJ, et al. Appraisal of concomitant splenectomy in liver resection for hepatocellular carcinoma in cirrhotic patients with hypersplenic thrombocytopenia. Surgery. 2004;136(3):660-8.

19. Hanazaki K, Kajikawa S, Adachi W, Amano J. Portal vein thrombosis may be a fatal complication after synchronous splenectomy in patients with hepatocellular carcinoma and hypersplenism. J Am Coll Surg. 2000;191(3):341-2.

20. Oh JW, Ahn SM, Kim KS, Choi JS, Lee WJ, Kim BR. The role of splenectomy in patients with hepatocellular carcinoma and secondary hypersplenism. Yonsei Med J. 2003;44(6):1053-8.

21. Kim SH, Kim do Y, Lim JH, Kim SU, Choi GH, Ahn SH, et al. Role of splenectomy in patients with hepatocellular carcinoma and hypersplenism. ANZ J Surg. 2013;83(11):865-70.

22. Wang C, Li C, Wen TF, Yan LN, Li B, Liang GL, et al. Safety of synchronous hepatectomy and splenectomy for patients with hepatocellular carcinoma and hypersplenism. Hepatogastroenterology. 2012;59(114):526-8.

23. Zhang Y, Wen TF, Yan LN, Yang HJ, Deng XF, Li C, et al. Preoperative predictors of portal vein thrombosis after splenectomy with periesophagogastric devascularization. World J Gastroenterol. 2012;18(15):1834-9.

24. Ikeda M, Sekimoto M, Takiguchi S, Kubota M, Ikenaga M, Yamamoto H, et al. High incidence of thrombosis of the portal venous system after laparoscopic splenectomy: a prospective study with contrast-enhanced CT scan. Ann Surg. 2005;241(2):208-16.

25. Kinjo N, Kawanaka H, Akahoshi T, Tomikawa M, Yamashita N, Konishi K, et al. Risk factors for portal venous thrombosis after splenectomy in patients with cirrhosis and portal hypertension. Br J Surg. 2010;97(6):910-6. 
26. Takayama T, Makuuchi M, Yamazaki S, Hasegawa H. The role of splenectomy in patients with hepatocellular carcinoma and hypersplenism as an aid to hepatectomy. Nihon Geka Gakkai Zasshi. 1989;90(7):1043-8.

27. Coon WW. Splenectomy for thrombocytopenia due to secondary hypersplenism. Arch Surg. 1988;123(3):369-71.

28. Cescon M, Sugawara Y, Takayama T, Seyama Y, Sano K, Imamura H, et al. Role of splenectomy in living-donor liver transplantation for adults. Hepatogastroenterology. 2002;49(45):721-3.

Submit your next manuscript to BioMed Central and we will help you at every step:

- We accept pre-submission inquiries

- Our selector tool helps you to find the most relevant journal

- We provide round the clock customer support

- Convenient online submission

- Thorough peer review

- Inclusion in PubMed and all major indexing services

- Maximum visibility for your research

Submit your manuscript at www.biomedcentral.com/submit 